\title{
POR UMA PRÁTICA DIALÓGICA CONTEMPORÂNEA: BAKHTIN E AS TDIC NA PRODUÇÃO ESCRITA
}

\author{
PARA UNA PRÁCTICA DIALÓGICA CONTEMPORÁNEA: BAKHTIN Y TDIC EN LA \\ PRODUCCIÓN ESCRITA
}

\section{FOR A CONTEMPORARY DIALOGIC PRACTICE: BAKHTIN AND TDIC IN WRITTEN PRODUCTION}

\author{
Paulo Alexandre FILHO ${ }^{1}$ \\ Solange Aparecida de Souza MONTEIRO ${ }^{2}$ \\ Paulo Rennes Marçal RIBEIRO ${ }^{3}$
}

RESUMO: O artigo em questão tem como objetivo propor uma sequência metodológica, envolvendo a produção escrita atrelada à perspectiva dialógica de Bakhtin na contemporaneidade. Para tanto, contará com as TDIC e suas múltiplas possibilidades de uso na época atual. Dessa forma, o contexto de reflexão será explorado sincronicamente tendo como parâmetro a publicação da BNCC (2018) e o atual momento da educação brasileira para fins de confronto, reflexão e proposição. Logo, busca-se atrelar a teoria dos gêneros discursivos às TDIC, ressaltando as necessidades de incorporar tais recursos em situações pedagógicas, sem perder de vista, o texto enquanto unidade básica de ensino, dotado de ideologia e com intencionalidade.

PALAVRAS- CHAVE: TDIC. Dialogismo. Produção escrita.

RESUMEN: El artículo en cuestión tiene como objetivo proponer una secuencia metodológica, que implica la producción escrita vinculada a la perspectiva dialógica de Bakhtin en los tiempos contemporáneos. Para eso, contará con TDIC y sus múltiples posibilidades de uso en el momento actual. De esta manera, el contexto de reflexión se explorará de forma sincronizada con la publicación del BNCC (2018) y el momento actual de la educación brasileña con el propósito de confrontar, reflexionar y proponer como parámetro. Por lo tanto, el objetivo es vincular la teoría de los géneros discursivos con el TDIC, enfatizando la necesidad de incorporar dichos recursos en situaciones pedagógicas, sin perder de vista el texto como una unidad de enseñanza básica, dotada de ideología e intencionalidad.

PALABRAS CLAVE: TDIC. Dialogismo. Producción escrita.

${ }^{1}$ Universidade Estadual Paulista (Unesp), Assis - SP - Brasil. Professor efetivo do Quadro de Magistério da Secretaria Estadual de Educação do Governo do Estado de São Paulo. Mestre em Linguística e Língua Portuguesa. ORCID: https://orcid.org/0000-0002-4613-3082. E-mail: palexandre2014@ outlook.com

${ }^{2}$ Universidade Estadual Paulista (Unesp), Araraquara - SP - Brasil. Doutoranda em Educação Escolar. Pedagoga IFSP, Araraquara. ORCID: https://orcid.org/0000-0002-1640-0266. E-mail: solmonteiro@ifsp.edu.br

${ }^{3}$ Universidade Estadual Paulista (Unesp), Araraquara - SP - Brasil. Docente e Coordenador do Programa de Pósgraduação em Educação Sexual. Docente PPG em Educação Escolar. ORCID: https://orcid.org/0000-0002-15525702. E-mail: paulo.rennes@unesp.br

Temas em Educ. e Saúde, Araraquara, v. 16, n. 1, p. 173-186, jan./jun., 2020. e-ISSN 2526-3471. 
ABSTRACT: This article aims at proposing a didactic sequence involving written production linked to the Bakhtin dialogical perspective in contemporaneity. For this purpose, it will count on the DICTs and their multiple possibilities of use in the current era. Therefore, the reflection context will be explored synchronically, taking the BNCC as a parameter and the current situation of the Brazilian education for confrontation, reflection and proposition. Therefore, it aims at linking the discursive theory of genres to DICTs, emphasizing the need to incorporate this resource in pedagogical situations, without losing sight of the text as a basic unit of education, endowed with ideology and intentionality.

KEYWORDS: DICTs. Dialogism. Writing production.

\section{Introdução}

Em plena Era do Conhecimento, na qual inclusão digital e Sociedade da Informação são termos cada vez mais frequentes, o ensino não poderia se esquivar dos avanços tecnológicos que se impõem ao nosso cotidiano (PEREIRA, 2007, p. 13).

Trabalhar a produção escrita nas aulas de língua portuguesa é e sempre será um desafio, pois exige de todos que se inserem nesse processo, tanto professor, quanto aluno, competências e habilidades que perpassam a ação de materializar palavras. Dessa forma, não só aluno como também professor tornam-se aprendentes por meio de uma relação horizontal envolvendo trocas constantes, transformando-se em interlocutores constantes e, ao mesmo tempo, promovendo confrontos cognitivos para ambos que juntos travam uma luta entre "aquilo a ser dito" e "como transformar isso em palavras".

Em meio a esse contexto, inúmeros são os fatores que tornam o ato da escrita sofrível para ambos, que vão desde as dificuldades em operar com o sistema linguístico até a falta de ideias para iniciar o texto. Entretanto, o que se evidencia em meio a tudo isso é a ausência de um objetivo concreto que motive os alunos a produzirem textos que, de fato, ocupem papel de relevância, não somente enquanto material para fins de avaliação, mas, sobretudo, enquanto ferramenta de cidadania. Assim, notamos situações de produção escrita que se destinam única e exclusivamente para aferir domínio de língua/linguagem, de modo a anular o papel social tanto do autor quanto do texto produzido.

Os PCNs (1998) de língua portuguesa para os $3^{\circ}$ e $4^{\circ}$ ciclos já traziam como proposta para o ensino de língua materna uma abordagem discursiva para as aulas de produção escrita em que a noção de "gêneros" ocupa espaço e relevância no contexto escolar. Desde então, as aulas deveriam contemplar e, ao mesmo tempo, atender aspectos que fossem além do ato de escrever, pois no contexto de produção estão inseridos elementos de ordem ideológica e de 
cidadania que merecem ser valorizados inclusive nas práticas discursivas em sala de aula. Para tanto consideremos as seguintes afirmações conforme apresenta os PCNs:

Para isso faz-se necessária uma proposta educacional que tenha em vista a qualidade da formação a ser oferecida a todos os estudantes. $\mathrm{O}$ ensino de qualidade que a sociedade demanda atualmente expressa-se aqui como a possibilidade de o sistema educacional vir a propor uma prática educativa adequada às necessidades sociais, políticas, econômicas e culturais da realidade brasileira, que considere os interesses e as motivações dos alunos e garanta as aprendizagens essenciais para a formação de cidadãos autônomos, críticos e participativos, capazes de atuar com competência, dignidade e responsabilidade na sociedade em que vivem (PCNs, 1998, p. 27).

Dessa forma, nota-se, já nos PCNs (1998), uma preocupação real em articular o ensino da língua materna com aspectos de cultura e de cidadania para conferir "sentido" às produções escritas. Entretanto, duas décadas após sua publicação, observamos que a condição de letramento no país ainda está aquém do que se espera. É de comum acordo que as competências leitora e escritora dos brasileiros são precárias, tendo em vista os índices de proficiência da linguagem que demonstram e as dificuldades quando o assunto envolve habilidades de leitura e escrita.

Transformações impactam diretamente em todas as instâncias sociais inclusive na educação. O documento dos PCNs (1998) ampara-se numa perspectiva bakhtiniana de gêneros discursivos para as aulas de produção textual, o que é muito coerente para as práticas de linguagem no contexto escolar. Contudo, o momento atual, em virtude dos avanços tecnológicos, exige, por parte do educador e instituições de ensino, um olhar acurado no intuito de articular, arrojar e implementar novas possibilidades de ensino sem perder de vista as modernidades advindas da tecnologia, assim como podemos comprovar a partir da aprovação da BNCC (2018) (Base Nacional Comum curricular). Portanto, fica clara a necessidade de buscar alternativas que possibilitem unir teoria e realidade sem que haja negligência de aspectos relacionados às transformações sócio-históricas, entre elas as TDIC. De acordo com a nova proposta da BNCC (2018):

Todo esse quadro impõe à escola desafios ao cumprimento do seu papel em relação à formação das novas gerações. É importante que a instituição escolar preserve seu compromisso de estimular a reflexão e a análise aprofundada e contribua para o desenvolvimento, no estudante, de uma atitude crítica em relação ao conteúdo e à multiplicidade de ofertas midiáticas e digitais. Contudo, também é imprescindível que a escola compreenda e incorpore mais as novas linguagens e seus modos de funcionamento, desvendando possibilidades de comunicação (e também de manipulação), e que eduque para usos mais democráticos das tecnologias e para uma participação mais consciente na cultura digital. Ao aproveitar o potencial de comunicação do

Temas em Educ. e Saúde, Araraquara, v. 16, n. 1, p. 173-186, jan./jun., 2020. e-ISSN 2526-3471. 
universo digital, a escola pode instituir novos modos de promover a aprendizagem, a interação e o compartilhamento de significados entre professores e estudantes (BNCC, 2018, p. 61).

O desenvolvimento tecnológico trouxe para a sociedade recursos que em muito facilitaram a vida contemporânea. Assim, com a imersão em transformações, viver, nos dias de hoje, implica não apenas ter acesso às condições de subsistência, como também ter acesso aos inúmeros recursos que a tecnologia pode proporcionar. Para o homem moderno, o conceito de qualidade de vida atrela-se fundamentalmente às comodidades que tais mudanças podem oferecer a ele. Tal aspecto se fundamenta, quando é notória a preocupação da gestão pública e empresas privadas em expandir pontos de redes wi-fi como forma de oportunização e, ao mesmo tempo, socialização desse bem de consumo, atualmente, preponderante nas relações sociais.

Nesse sentido, ao relacionar o papel e o potencial das tecnologias digitais na sala de aula, observa-se a educação brasileira à margem de tudo isso. Há algum tempo, o sistema educacional no país demonstra "cansaço", atrelado a metodologias e recursos já ultrapassados. Dessa forma, para o jovem, o contexto de ensino constitui-se como desestimulante. Claro que atrelar tecnologia e aprendizagem no ambiente escolar não é fácil, tendo em vista os problemas, tanto de ordem burocrática ou no que tange à infraestrutura de nossas instituições de ensino. Contudo, giz, lousa e livro didático ainda ocupam, enquanto instrumentos didáticopedagógicos, o protagonismo do processo ensino-aprendizagem, como se a escola ocupasse uma realidade a parte daquela que realmente vivenciamos em nosso dia a dia. Surge, desse modo, a inquietação: como, no atual contexto tecnológico, aceitar que as ferramentas mais utilizadas pelos estudantes estejam fora do panorama educacional?

\begin{abstract}
Se levarmos em conta a gama diversa de textos disponíveis, a escola ainda se restringe ao texto impresso e não prepara o aluno para a leitura de textos em diferentes mídias. É de suma importância que a escola proporcione aos alunos o contato com diferentes gêneros, suportes e mídias de textos escritos, através, por exemplo, da vivência e do conhecimento dos espaços de circulação dos textos, das formas de aquisição e acesso aos textos e dos diversos suportes da escrita. Ela também pode incorporar cada vez mais o uso das tecnologias digitais para que os alunos e os educadores possam aprender a ler, escrever e expressar-se por meio delas (LORENZI; PÁDUA, 2012, p. 36).
\end{abstract}

Diante dessa realidade, pensar e reavaliar as potencialidades das TDIC como ferramentas pedagógicas significa romper com paradigmas e, simultaneamente, abrir-se para outras perspectivas envolvendo ensino-aprendizagem. Para tanto, procurar maneiras de articular o ensino da língua portuguesa a situações de aprendizagem significativas e alcançar 
resultados satisfatórios nos atos de letrar e desenvolver proficiência nas competências leitora e escritora tornou-se fundamental para os tempos de hoje.

\section{Aspectos teóricos}

O termo "hipermodernidade" emerge no intuito de não apenas nomear uma fase da História, mas, sobretudo, caracterizar um fenômeno complexo que se estende a todas as camadas sociais sem descartar que seus impactos são de ordem universal e irreversível. Desse modo, surge uma sociedade com ações centralizadas, (inter) mediadas e/ou subsidiadas por uma teia em que a tecnologia se faz presente a todo instante. Logo "pode-se perceber, na atualidade, uma dependência total do homem em relação à máquina e à tecnologia para sobreviver. $\mathrm{O}$ mundo é marcado pela inteligência artificial, sendo a dependência uma de suas características" (RIBEIRO, 2007, p. 85).

Em meio a tal contexto, a modernidade que instantaneamente se transmuta numa realidade "hiper" exige, concomitantemente, de tais transformações mudanças significativas, inclusive, no caráter comportamental, de forma que as implicações recaiam, inclusive, nas interações entre humanos, ou seja, padrões e conceitos se tornam fluidos e com múltiplas possibilidades de modificação e/ou adaptação. Por conseguinte, a busca por informação e a necessidade de expressar-se em novas plataformas são mais recorrentes na contemporaneidade, assim como sua forma de interagir socialmente passa do "eu" para o "nós" de modo que construções "centrífugas" e não mais "centrípetas" se revelam e se interceptam nesse novo panorama.

O homem cede espaço para a construção de um sujeito coletivo que, aos poucos, tomou o lugar das subjetividades e individualidades. O sujeito é o elo de uma teia de relações, formando um ecossistema, no qual, sozinho, não é ninguém. $\mathrm{O}$ indivíduo carrega em si um sistema aberto que deve propiciar um trabalho interessante e interativo (RIBEIRO, 2007, p. 85).

No artigo em questão, utilizar-se-á uma perspectiva textual pautada nas concepções de Bakhtin/Volochínov em que os signos incorporam ideologias numa cadeia de complexidade até transmutarem-se em gêneros discursivos, que por sua vez, constituem-se e materializam-se a partir de realidades sociais concretas.

Sabemos que cada palavra se apresenta como uma arena em miniatura onde se entrecruzam e lutam os valores sociais de orientação contraditória. A palavra revela-se, no momento de sua expressão, como o produto da interação viva das forças sociais. É assim que o psiquismo e a ideologia se impregnam 
mutuamente no processo único e objetivo das relações sociais (BAKHTIN, 2014, p. 67).

Embasar-se em Bakhtin para discutir o uso das ferramentas digitais na atualidade com objetivo de oportunizar situações de aprendizagem, propondo um trabalho com a produção escrita numa perspectiva de gêneros discursivos se faz extremamente relevante, pois "ações hoje concretas e nomeadas, como etiquetar/taguear, seguir, curar, apreciar (curtindo, comentando, redistribuindo ou reblogando), remixar e hibridizar enunciados no discurso já previstos por Bakhtin/Volochínov" (ROJO; BARBOSA, 2015, p. 124). Sendo assim, os gêneros discursivos acompanhados das múltiplas possibilidades oferecidas na atualidade serão alicerces para a contextualização e reflexão envolvendo as tecnologias, em especial, as digitais cada vez mais presentes no cotidiano de estudantes e professores.

\section{Onde estamos? Do letramento aos multiletramentos: na interface dos problemas}

Antes de iniciar propriamente a reflexão acerca de uma proposta de produção escrita contemplando gêneros discursivos e TDIC, é preciso esclarecer o papel da escola nesse processo de ensino-aprendizagem. Enquanto instituição pedagógica não se deve descartar sua função "metodológica" (por que não dizer "metódica"?) de preparar seus alunos para avaliações das instituições de ensino superior (vestibular) e concursos públicos. Todavia, o que se nota é um trabalho focado apenas em cumprir listas de conteúdos, competências e habilidades exigidas por tais exames em detrimento de um trabalho mais amplo com a linguagem. No que se refere aos aspectos envolvendo linguagem escrita, na condição de educadores, precisamos ter clareza de nossos objetivos: queremos aulas de redação ou produção escrita?

Numa perspectiva menos apurada, poder-se-ia afirmar que tanto "produção de texto" quanto "redação" significam a mesma coisa. Entretanto, a partir de uma análise com maior acuidade, nota-se que a relação entre uma e outra é divergente e, ao mesmo tempo, por que não dizer excludente? João Wanderley Geraldi, nos anos 80, por meio da obra "O texto na sala de aula" (1984), problematiza o fato ao confrontar dois textos de alunos do $1^{\circ}$ ano (Anos iniciais). Em um deles, percebe-se a construção de uma unidade obedecendo todas as normas da escritapadrão, ao passo que o segundo continha erros gramaticais e evidenciava uma “despadronização" da linguagem (ortografia, pontuação, repetição, etc.). Para tanto nessa problemática o autor enfatiza:

É devolvendo o direito à palavra - e na nossa sociedade isto inclui o direito à palavra escrita - que talvez possamos um dia ler a história contida, não

Temas em Educ. e Saúde, Araraquara, v. 16, n. 1, p. 173-186, jan./jun., 2020. e-ISSN 2526-3471. 
contada, da grande maioria que hoje ocupa os bancos das escolas públicas. E tal atitude, parece-me, dá um novo significado à questão "como avaliar redações?" (GERALDI, 2012, p. 131).

A grande polêmica do caso descrito acima só se evidencia quando a análise das produções, passa pelo critério de texto enquanto unidade de sentido. Sendo assim, comprovouse que aquele que escreveu dentro dos "padrões" não se mostrava no texto como um sujeito que tem algo a dizer, ou seja, para este, escrever não significa enxergar na produção escrita o espaço do "expressar-se". Já o outro, que inclusive reprovou de ano, conferiu à sua escrita um "sentido" que vai além dos aspectos linguísticos.

Portanto, a escola está num impasse que vai muito além da noção de texto, pois no caso ilustrado, percebemos outras questões subjacentes à problemática que perpassam o domínio da linguagem formal e atingem uma questão de ordem social: a descaracterização do aluno enquanto sujeito. Geraldi (2014), em "Por que práticas de produção de texto, de leitura e análise linguista?", ressalta:

A linguagem como uma atividade constitutiva dos sujeitos, cujas consciências, sendo sígnicas - e, portanto, ideológicas-, eram marcadas pelos processos interativos de que participavam, tomando estes desde seu sentido mais estrito do diálogo face a face até seu sentido mais amplo abrangendo um tempo, um espaço, uma história sociais. Foi a compreensão inicial desse processo de constituição que me levou a defender o ponto de vista de que considerar erro qualquer variante da língua padrão era considerar errado o próprio processo de constituição dos sujeitos que falavam variedades distintas (GERALDI, 2014, p. 210).

A partir disso, Geraldi demonstra a necessidade da escola não apenas solicitar e/ou avaliar "redação", mas sim "produção de texto". Segundo ele, não se trata apenas de nomenclatura, uma vez que a segunda se liga intimamente a um papel político-social, enquanto que a primeira apenas exige domínio de uma estrutura e linguagem padronizadas. Portanto, ao estabelecer uma analogia entre a situação descrita e o contexto educacional contemporâneo, percebemos, infelizmente, que não houve mudança significativa. Pelo contrário, o que houve foi apenas uma mudança na ordem das nomenclaturas com olhar e práticas já ultrapassadas.

Desse modo, infelizmente, ainda notamos que a escola persiste em destituir o caráter de sujeito social do estudante, perpetuando modelos tradicionais que privilegiam aspectos apenas normativos da linguagem sem contexto e sem reflexão longe do papel social do texto. Em outras palavras, sem lhe conferir um letramento que vai além da funcionalidade de pequenas práticas do cotidiano em vez de uma concepção de linguagem revolucionária capaz de refletir, agir e transformar uma realidade. 


\title{
Uma proposta metodológica de produção escrita atrelada aos gêneros discursivos e às TDIC
}

Em virtude das complexidades dos diversos contextos de ensino-aprendizagem e para fins de didatização, surge a BNCC (2018) que além de priorizar o uso social da linguagem e a concepção de gênero como forma ideal para abordar língua e linguagem nas aulas de língua portuguesa, também traz consigo as TDIC como recurso fundamental para se trabalhar com a língua materna atualmente. Essa forma de abordar língua/linguagem, tendo como intuito a produção escrita, partindo de situações concretas e evolvendo as tecnologias requer do professor dois grandes desafios: autonomia e clareza. Dessa forma, ao tomar o texto como unidade de aprendizagem, o planejamento se torna essencial para que de fato a aula possa assumir seu caráter dialógico e atenda àquilo que se pretende.

\begin{abstract}
Um dos problemas constatados nas redações escolares é precisamente este: não se define com precisão a quem o aluno se dirige. A cena textual não fica clara. Ele não tem um outro (o auditório) bem determinado e assim tem dificuldade de operar com a linguagem e escreve tudo para o mesmo interlocutor que é o professor. E nós sabemos que a mudança de interlocutor leva a se fazer seleções lexicais diversas e níveis de formalidade distintos (MARCUSCHI, 2008, p. 78).
\end{abstract}

Quando se fala de autonomia para que se tenha um trabalho satisfatório, em hipótese alguma, deve-se confundi-la com subversão, pelo contrário, entende-se nesse aspecto um olhar maduro e perspicaz por parte do professor que diante de uma situação concreta pode extrair daí uma possibilidade de trabalhar a produção escrita. Já no que diz respeito à clareza daquilo que se pretende, é de comum acordo que se não houver entendimento e planejamento do percurso pretendido, o trabalho tenderá ao fracasso independente do recurso ou metodologia utilizados. Nesse sentido, concordamos com Moran (2013, p. 27) "não há tecnologias avançadas que salvem maus profissionais."

Logo, esses dois aspectos essenciais para a abordagem da língua/linguagem como instrumento de materialização do texto requerem um outro aspecto: formação. Claro que diante dos inúmeros problemas que nos assolam como carga horária, jornada dupla entre outras tantas, o caráter formativo deve acompanhar o educador durante todo seu trajeto na educação, pois precisamos nos assegurar de condições mínimas de conhecimento para assim efetivarmos um trabalho profícuo e de resultado satisfatório.

Até o presente momento já discriminamos pontos muito relevantes para uma abordagem de ensino envolvendo produção escrita: teoria (gêneros discursivos), autonomia, clareza e formação. Mas onde entram as TDIC em meio a isso tudo? Pois bem, as TDIC, inseridas no 
contexto da sala de aula, serão o elo entre todos esses elementos no intuito de trazer "realidade" para as aulas de língua portuguesa.

De antemão o que se pretende com essas reflexões acerca de aspectos envolvendo a escrita é promover possibilidades de mudanças que tocam na estrutura metodológica tradicional, focalizando teoria e realidade através de um movimento coletivo, envolvendo escola, aluno, professor e metodologias. Vale ressaltar que, em nenhum momento, há pretensão de assumir papel prescritivo diante de práticas pedagógicas e/ou profissionais da educação, mas sim, procurar caminhos que permitam o uso de outras ferramentas na rotina escolar.

Diante da gama de possibilidades e recursos oferecidos pela realidade do século XXI, um trabalho embasado por Bakhtin de modo a explorar os gêneros digitais seria o mais coerente. As redes sociais, por exemplo, podem servir de suporte para que situações concretas de produção escrita levem ao letramento sem desprezar o caráter responsivo do enunciado/ enunciador linguístico. Transitar entre as diversas possibilidades de materialização do texto (gêneros discursivos) ainda mais na configuração digital, não é fácil, entretanto se faz relevante para o contexto atual.

Uma proposta metodológica, envolvendo produção escrita, como já foi apontado anteriormente, requer do professor autonomia, clareza, formação e, principalmente, planejamento das ações e dos percursos. No caso deste artigo, tomaremos uma situação hipotética e que pode se aplicar genericamente podendo ser alterada conforme às diferentes realidades, quando necessário.

Para que o texto nasça a partir de uma realidade concreta, o professor deve estar atento ao contexto que circunda escola e alunos seja ele em larga ou micro escala. Entende-se esta como cidade, bairro, família, etc. Já aquela pode ser compreendida como o país, ou seja, o "macro", que por sua vez se reflete verticalmente sobre a sociedade como um todo. Logo, é necessário se abrir ao diálogo com os alunos, entender suas realidades, captar aquilo que lhes interessa mais e de que forma a linguagem serviria como forma de expressar seus anseios ou expectativas.

Dessa forma, suponhamos que no contexto micro da maioria dos alunos haja um problema de saneamento básico, de modo que tal situação incomode a comunidade. Diante dessa situação concreta, pode-se instigar os alunos e levá-los a uma reflexão e demonstrar que através da linguagem e das plataformas digitais pode-se dar notoriedade ao "incômodo" e assim talvez ter a solução do problema. Nesse momento, não se deve negligenciar um fato concreto e rico que privilegia uma produção escrita "real" em detrimento de uma lista de conteúdo programático, ou seja, aqui entra a autonomia do professor. 
Passada essa fase envolvendo situação concreta e conscientização da linguagem enquanto ferramenta social para exercício de cidadania, é preciso partir para a fase de planejamento. Nesse momento, deve-se coletar e registrar o fato motivador da aula, portanto, as TDIC terão importância fundamental, uma vez que, no contexto da hipermodernidade, a maioria dos alunos pode acessá-las e usá-las sem grandes problemas. Diante disso, o professor poderá em conjunto com eles selecionar o gênero discursivo que será trabalhado a partir dos objetivos da turma. Na situação hipotética, acredita-se que os gêneros discursivos de natureza argumentativa sejam mais coerentes. Entretanto, poderia ser de natureza narrativa ou uma outra, sem nenhum problema, desde que atenda aos objetivos dos estudantes e do professor, daí também a importância do grau de formação do educador.

Nesse processo de planejar a partir de uma situação concreta, a delimitação do tempo é fundamental e fica a cargo do conhecimento e bom-senso do educador. Como já apontamos, os recursos digitais acompanham todo o percurso envolvendo a sequência enquanto ferramenta de ensino-aprendizagem. As estratégias são variadas e podem envolver publicações com enquetes em redes sociais, grupos para discussão e reflexão no WhatsApp, chamadas de vídeo e vlogs como forma de interação e divulgação das etapas. Enfim, o contexto de aprendizagem tendo as tecnologias digitais a seu favor pode gerar e/ou adaptar recursos que são manipulados facilmente pelos jovens.

Coletado o material, refletido sobre a situação-problema e definido o gênero, é hora de escrever. Como foi dito no início do artigo, a tarefa de escrever não é fácil, pois há inúmeros fatores que nela interferem sistematicamente. Segundo Pereira (2014), para Bakhtin, o momento da escrita envolve dois grupos de força que agem sobre texto e autor: força centrípeta e força centrífuga. A primeira norteia e delimita construções coerentes para o gênero discursivo, ao passo que a segunda, busca e testa dentre as inúmeras hipóteses e possibilidades aquilo que se acomodará no contexto discursivo.

\footnotetext{
Portanto, Bakhtin postula a existências de duas forças que operam nos gêneros: uma que os estabilizam e os tornam homogêneos (forças centrípetas), e outra que os desestabilizam e os tornam heterogêneos (forças centrífugas). Essas forças genéricas estão relacionadas com a padronização dos gêneros. Segundo o teórico, há gêneros que não possibilitam muitas inovações, como é o caso de um requerimento, por exemplo, que apresenta elementos constitutivos mais rígidos, tornando-o mais estável; mas há outros mais acomodatícios a entradas individuais, exemplificados pelo autor como sendo os gêneros literários (PEREIRA, 2014, p. 01).
}

Durante o processo de escrita, pode-se explorar o uso da web ou aplicativos para fins de pesquisa. A todo instante, o objetivo da produção escrita precisa ser reiterado, ressaltando o 
papel da linguagem como forma de expressão e representação de uma realidade. A atitude ética e responsiva enquanto sujeito de produção e/ou recepção do texto precisam ser trabalhadas também, pois o discurso de ódio e/ou intolerância nas redes sociais deve ser combatido, repudiado e trabalhado no transcorrer das aulas.

Por fim, após escrita e intervenção do professor, é o momento de divulgar o texto em alguma plataforma digital. Para que se atenda ao objetivo de alcançar o maior número de leitores, uma boa estratégia é "taguear" a postagem, bem como marcar outros usuários da web e, assim, conduzir a produção textual até o leitor de modo a sensibilizá-lo e incentivá-lo a uma resposta (comentário) que automaticamente será devolvida aos autores do texto que julgarão pertinente ou não a devolutiva, encadeando, dessa maneira, uma teia discursiva a partir de enunciados e autores diversos.

Nesse percurso envolvendo produção escrita, tendo como ponto de partida uma situação concreta que por sua vez também terá um objetivo concreto, percebemos o papel fundamental das TDIC como recursos para materialização e divulgação do texto. Sendo assim, as aulas de língua portuguesa incorporam uma perspectiva discursiva e dialógica em relação ao ato de produzir texto ao mesmo tempo que se intersecciona com a realidade atual.

\section{Considerações finais}

Precisamos ter claro em nossa cabeça que melhor que um professor ensinar, é um aluno aprender (COSCARELLI, 2007, p. 26).

A partir da concepção de Geraldi (2012) de que o texto é a "partícula elementar" no processo de ensino-aprendizagem, as práticas escolares devem se pautar no engajamento social para que assim, por meio de uma relação discursiva, não percam seu caráter também elementar tanto de libertação quanto de integração do sujeito na esfera social. Quando trazemos à tona uma reflexão, envolvendo a metodologia utilizada atualmente para trabalhar a produção escrita e propomos uma abordagem que insere a perspectiva discursiva de Bakhtin dentro da hipermodernidade, não é no intuito de promover uma receita.

Pelo contrário, o artigo em questão se constitui em apenas uma sugestão com o objetivo de chamar atenção de todos os envolvidos na esfera educacional para a necessidade de se adequar nossas práticas, à medida que a sociedade evolui. A escola nos dias atuais tem o papel de preparar o aluno de maneira integral para que este torne-se apto para os desafios da sociedade contemporânea. 
Diante dessa necessidade em adequar prática e realidade, não negligenciamos os inúmeros entraves acerca dessa situação. Entretanto, podemos planejar esse trabalho esporadicamente como forma de observação e reflexão das práticas tradicionais e vigentes no contexto escolar. Trazer as TDIC para as situações de ensino- aprendizagem não nos assegura em hipótese alguma um resultado plenamente satisfatório num primeiro momento, pois assim como afirma Coscarelli (2007, p. 26) "o fato de usar a informática nas aulas não transforma instantaneamente o ensino em alguma coisa 'moderna' e 'eficiente"'.

Entretanto, é preciso ousar e buscar novas práticas que estimulem e tornem as situações de aprendizagem pertinentes com a realidade em que o aluno se insere, logo "os professores precisam encarar esse desafio de se preparar para essa nova realidade, aprendendo a lidar com os recursos básicos e planejando formas de usá-los em suas salas de aula” (COSCARELLI, 2007, p. 31).

Para finalizar, reiteramos os pontos aqui elencados durante a proposta metodológica (autonomia, clareza, formação e planejamento) e ressaltamos o papel fundamental da "formação". Não se pode cobrar do professor práticas reais, envolvendo situações de discursividade, se o mesmo foi vítima de uma universidade que também não apontou possibilidades e estratégias para se trabalhar com a linguagem sem desprezar o contexto de produção e todos os recursos, principalmente, os digitais que tanto podem lhe apoiar nesse processo. Outro aspecto contrário está nos centros de formação envolvendo secretarias e diretorias de ensino que não oportunizam cursos de formação adequados para as novas realidades.

Enfim, a reflexão aqui proposta é no intuito não apenas de mobilizar, mas, sobretudo, provocar uma (re)ação em todos os agentes inseridos no processo educacional, de modo que condições adequadas de letramento se tornem comuns na educação sem negligenciar autor, texto e contexto de ensino.

\section{REFERÊNCIAS}

BAKHTIN, M. (VOLOCHÍNOV). Marxismo e filosofia da linguagem. Trad. Michel Lahud e Yara Frateschi Vieira. 16. ed. São Paulo: Hucitec, 2014. p. 204.

BAKHTIN, M. Estética da Criação Verbal. Trad. Paulo Bezerra. 6. ed. São Paulo: Editora WMF, 2011. p. 476.

BRASIL. Parâmetros Curriculares Nacionais (PCNs). Brasília: MEC/SEF, 1998. Disponível em: http://portal.mec.gov.br/seb/arquivos/pdf/livro01.pdf. Acesso em: 16 de out. 2019. 
BRASIL. Base Nacional Comum Curricular (BNCC): Educação é a Base. Brasília, DF: MEC, 2018. Disponível em:

http://basenacionalcomum.mec.gov.br/images/BNCC_EI_EF_110518_versaofinal_site.pdf. Acesso em: 16 de out. de 2019.

COSCARELLI, C. V. Alfabetização e letramento digital. In: COSCARELLI, C. V; RIBEIRO, A. E. et al., (Orgs.). Letramento digital: Aspectos sociais e possibilidades pedagógicas. 2. ed. Belo Horizonte: Autêntica Editora, p. 25-40, 2007.

DOLZ, J.; SCHNEUWLY, B. Gêneros orais e escritos na escola. Tradução e organização de Roxane Rojo e Glais Sales Cordeiro. 3. ed. Mercado das Letras, 2004.

GERALDI, J. W. Escrita, uso da escrita e avaliação. In: GERALDI, J. W et al., (Org.) $\mathbf{O}$ texto na sala de aula. 1. ed. São Paulo: Anglo, p. 127-131, 2012.

GERALDI, J. W. Por que práticas de produção de texto, de leitura e de análise linguística? In: SILVA, L. L. M. da; FERREIRA, N. S. de A.; MORTATTI, M. do R. L. et al., (Orgs.). O texto na sala de aula: um clássico sobre o ensino de língua portuguesa. Campinas: Autores Associados, p. 207-226, 2014.

LORENZI, G. C. C; PÁDUA, T. W. Blog nos anos iniciais do fundamental I. In: ROJO, R; MOURA, E. et al., (Orgs.). Multiletramentos na escola. 1. ed. São Paulo: Parábola Editorial, p. 35-54, 2012.

MARCUSCHI, L. A. Produção textual, análise de gêneros e compreensão. 3. ed. São Paulo: Parábola Editorial, p. 295, 2008.

MORAN, J. M. Ensino e aprendizagem inovadores com apoio de tecnologias. In: MORAN, J. M.; MASETTO, M. T.; BEHRENS, M. A. Novas tecnologias e mediação pedagógica. 21. ed. Campinas: Papirus, p. 11-72, 2013.

PEREIRA, J. T. Educação e sociedade da informação. In: COSCARELLI, C. V; RIBEIRO, A. E. et al., (Orgs.). Letramento digital: aspectos sociais e possibilidades pedagógicas. 2. ed. Belo Horizonte: Autêntica Editora, p. 13-24, 2007.

PEREIRA, M. H. M. Forças centrípetas e centrífugas atuando em três gêneros discursivos: narrativa de ficção, notícia e carta argumentativa. In: CONGRESSO INTERNACIONAL: ASSOCIACIÓN DE LINGUÍSTICA Y FILOLOGÍA DE AMÉRICA LATINA (ALFAL), 17., 2014, João Pessoa. Anais [...]. João Pessoa, Paraíba, 2014. Disponível em: https://www.mundoalfal.org/CDAnaisXVII/trabalhos/R0240-2.pdf. Acesso em: 15 de out. 2019.

RIBEIRO, J. O. Educação e novas tecnologias: um olhar para além da técnica. In: COSCARELLI, C. V; RIBEIRO, A. E. et al., (Orgs.). Letramento digital: aspectos sociais e possibilidades pedagógicas. 2. ed. Belo Horizonte: Autêntica Editora, 2007. p. 85-97.

ROJO, R; BARBOSA, J. Hipermodernidade, multiletramentos e gêneros discursivos. 1. ed. São Paulo: Parábola, p. 152, 2015. 


\section{Como referenciar este artigo}

FILHO, Paulo Alexandre; MONTEIRO, Solange Aparecida de Souza; RIBEIRO, Paulo Rennes Marçal. Por uma prática dialógica contemporânea: Bakhtin e as tdic na produção escrita. Temas em Educ. e Saúde, Araraquara, v. 16, n. 1, p. 173-186, jan./jun., 2020. e-ISSN 2526-3471. DOI: https://doi.org/10.26673/tes.v16i1.13922

Submetido em: 15/02/2020

Revisões requeridas: 20/04/2020

Aprovado em: 05/06/2020

Publicado em: 19/06/2020 